\title{
NEW COLD-EXPANSION PROCESS FOR END SIZING AND DIMENSIONAL PRECISION OF INSIDE GEOMETRY ON BOTH ENDS OF LINE PIPES
}

\author{
K. KURODA *, T. ARITA**, T. TAKANO***, H. OSAKO***, T. OKUI * \\ AND M. AKIYAMA ${ }^{\dagger}$ \\ * R \& D Laboratories \\ Nippon Steel \& Sumitomo Metal Corporation \\ 1-8 Fuso-cho, Amagasaki-shi, Hyogo, 660-0891, Japan \\ e-mail: kuroda.d88.kohichi@jp.nssmc.com \\ ** European Office \\ Nippon Steel \& Sumitomo Metal Corporation \\ Am Seestern 8, 40547 Düsseldorf, Germany \\ ${ }^{* * *}$ Wakayama Works \\ Nippon Steel \& Sumitomo Metal Corporation \\ 1850 Minato Wakayama, Wakayama 640-8555 Japan \\ ${ }^{\dagger}$ Research Institute of Applied Science \\ 49 Tanaka Ooi-cho, Kyoto, 606-8202, Japan
}

Key words: Line pipe, End sizing, Cold-expansion, Plug design, Double taper plug, Overshooting phenomenon.

\begin{abstract}
Cold-expansion process has been developed for ensuring dimensional precision of inside geometry on the end portions of line pipe. For expanding the inside diameter of line pipe, a plug insertion method by cold press in the axial direction from the end side was finally adopted. As the nature of end sizing operation, only very small amount of cold plastic strain is applicable by cold expansion, and in order to realize the high dimensional precision of end portion a special geometry of the plug had to be designed. If a single-taper plug is adopted the expanded portion tends to overshoot and the inside diameter of expanded portion is larger than the plug diameter. The new plug design allows smooth contact of the inside surface expanded by the inlet portion of the plug on the bearing portion of the plug and no overshooting phenomenon occurs. One of the simplest designs of this type of plug for practical use is a double-taper plug, and finite element method was carried out in order to determine the practical range of the plug geometry referring to the deep insight on the mechanism of expansion process.
\end{abstract}




\section{INTRODUCTION}

Recent trend of automated welding operation of line pipes requires high dimensional precision of inside geometry of parent pipes. For a smooth and speedy welding operation inside geometries of end portions of adjacent pipes which are facing each other must fall within a narrow range. Inside geometry of hot rolled line pipes is not necessarily perfectly round. Accordingly some pipes ought to be subjected to end-sizing process depending upon the requirement of the customer. There are various types of end-sizing process, but among those the following two processes are major; (1) expanding method using split tools, (2) pushing-in method using a plug. These two processes are simple and easy in operation but the latter is simpler because the movement of tool is limited only in the axial direction of the pipe whereas that of the former is at the beginning in the radial direction for expansion and then in the axial direction to finish drawing operation. Because of this reason, not only the operation but also the equipment for expansion can be realized for the latter. In adopting the latter method it is most important to design the geometry of tool appropriately in order to ensure the dimensional precision of expanded portion both in the cross section and in the axial direction. Namely, inside geometry of pipe must meet the plug diameter and for this purpose geometrical design of plug is most important.

It was not for the expansion process but for a swaging process that the authors showed that adoption of simple single taper die causes undershooting phenomenon and the outside diameter becomes slightly smaller than the inside diameter of die at the bearing portion [1]. In addition, the inside diameter after swaging is not necessarily uniform in the axial direction because of the unsteady deformation caused by the undershooting phenomenon. In order to suppress the undershooting phenomenon, the authors have proposed a double taper die for a relatively higher swaging ratio to suppress the undershooting phenomenon [2]. The key point of the new design was that appropriate design of the second taper portion of the double taper die [3], and the deformation throughout the swaging process becomes stable by adopting the proposed die design $[4,5]$.

Similar design philosophy was applied to the present cold expansion process. If a simple taper plug is adopted overshooting phenomenon occurs and the dimensional precision is not ensured both in a cross section and in the axial direction. In order to suppress this phenomenon it is effective to adopt a double taper plug [6] and appropriate geometry of the second taper portion was determined by carrying out by using implicit elastic-plastic finite element analyses (FEA). The code used for FEA was ELFEN developed at University of Wales Swansea [7]. It is important to note that only a small ratio of expansion is allowed because the dimension of end-sized portion must fall within the tolerance. After designing a double taper plug by FEA, laboratory experiment was carried out to validate the plug design. The result was an impact to the installation of new production line. The new production line is equipped with a new press machine for expansion and a measuring device of the geometry of the end-sized portion. The end-sizing line is able to deal with the outside diameter of line pipe up to 16 inches, and remarkable level of dimensional precision has been achieved. The details are as follows. 


\section{COMPARISON OF METHODS FOR END-SIZING}

Two major methods for end-sizing are (1) expanding method using split tools, (2) pushingin method using a plug. Schematic comparison of these methods is given in Figure 1. In the former a set of split segments of tool is inserted in the end portion of a pipe and is expanded for the outside surface of the segments to form a specified round profile either mechanically or hydraulically. Depending upon the length for end-sizing the tool can be drawn out of the pipe. However, because of this complicated sliding movement of the parts the outline of tool segments after expansion is not necessarily round both in a cross section and in the axial direction. In addition it is impossible to get rid of the wear of the working surfaces of sliding parts and the wear tends to be non-uniform both in the sliding direction and among the segments. The other disadvantage of this method is that perfectly round profile can never be formed by using a set of split segments of a tool. Because of these reasons uniform geometry of the inside surface of the formed end is not necessarily ensured. The latter, the pushing-in method using a plug, is free from this problem.

However, if one adopts a single taper plug with rather large plug angle, for example 10 degrees, the inside surface overshoots the plug surface and the inside geometry of expanded portion tends to be unstable similarly to the undershooting phenomenon in swaging [1,2 and 3]. In Figure 2 examples of overshooting phenomenon are shown. The material is a simple carbon steel for line pipes. It is clearly shown that the inside diameter of end-sized portion is larger than the plug diameter when a single taper plug is used for expansion. This difference must be avoided. In the case of swaging a double taper die is effective to suppress the undershooting phenomenon. Similar philosophy can be applicable to the over-shooting phenomenon and adoption of a double taper plug can be a key to a sound inside geometry of end-sized portion. Survey on an appropriate geometry of plug will be carried out in the following part of this paper by using FEA.

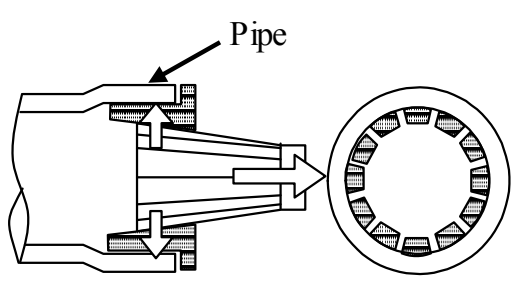

(a) Split-type tools

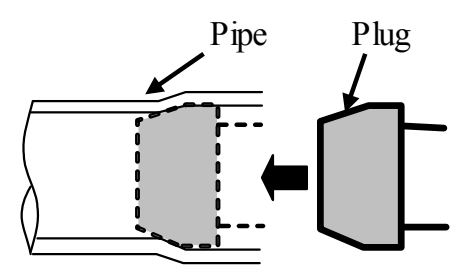

(b) Plug insertion method

Figure 1: Comparison of end-sizing methods

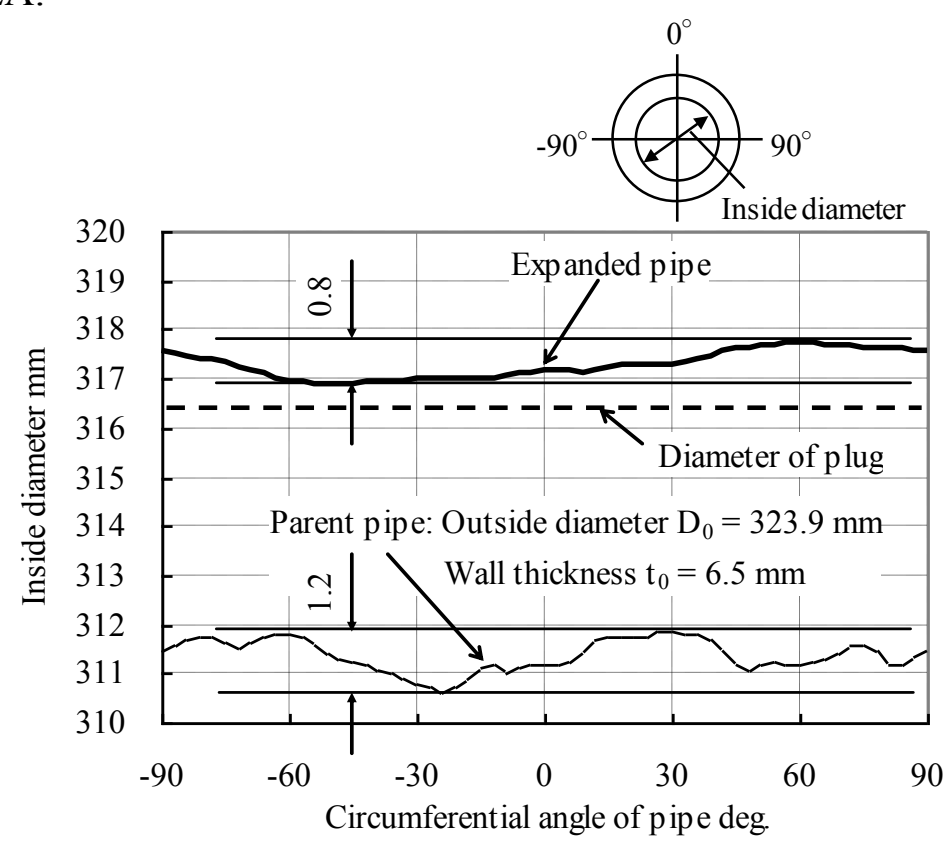

Figure 2: Technological target of new process 


\section{NEW PLUG GEOMETRY}

Implicit axis-symmetric elastic-plastic finite element analysis (FEA) was carried out to investigate the overshooting phenomenon. Table 1 shows the conditions for parent pipe and plug. The result is illustrated in Figure 3. The plug was a single taper plug and the dimensions of parent pipe and the plug are also illustrated in Fig. 3. It is clearly shown that overshooting phenomenon occurs and the inside surface of the worked pipe does not contact the bearing portion of the plug. Therefore the inside diameter is larger than the plug diameter which should determine the dimensional precision of the inside diameter of the end-sized portion when a single taper plug is adopted. Distributions of stress and strain continue to change slightly after the inside surface overshoots the plug, but they soon saturate.

In order to suppress the overshooting phenomenon a double taper plug was proposed and effect was investigated by using FEA. Comparison of the two plugs is illustrated in Figure 4.

The geometrical parameters were the angle and the length of the second taper portion. It was expected that the inside surface of pipe might smoothly contact the bearing portion if the geometry of the second taper portion was carefully selected to give to the pipe slight and additional expansion after the deformation by the first taper portion.

Table1 Conditions for parent pipe and plug

\begin{tabular}{rcc}
\hline Parent & Outside diameter $\mathrm{D}_{0} \mathrm{~mm}$ & 323.9 \\
\cline { 2 - 3 } pipe & Wall thickness $\mathrm{t}_{0} \mathrm{~mm}$ & 15.0 \\
\hline Single & Outside diameter $\mathrm{D}_{\mathrm{p}} \mathrm{mm}$ & 298.3 \\
\cline { 2 - 3 } $\begin{array}{r}\text { taper } \\
\text { plug }\end{array}$ & Angle of taper zone $\theta_{1} \mathrm{deg}$ & 5 \\
\cline { 2 - 3 } & Length of taper zone $\mathrm{L}_{1} \mathrm{~mm}$ & 100 \\
\cline { 2 - 3 } & Length of parallel zone $\mathrm{L}_{3} \mathrm{~mm}$ & 50 \\
\hline
\end{tabular}

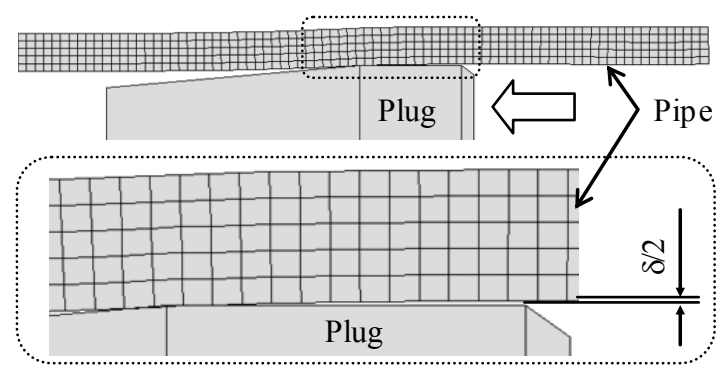

(a) Overshooting phenomenon

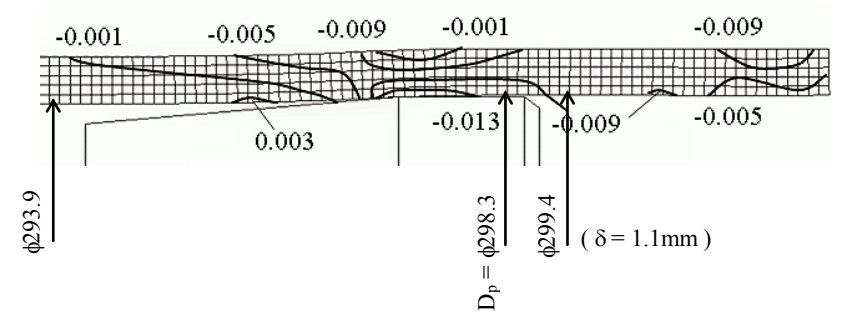

(b) Axial strain

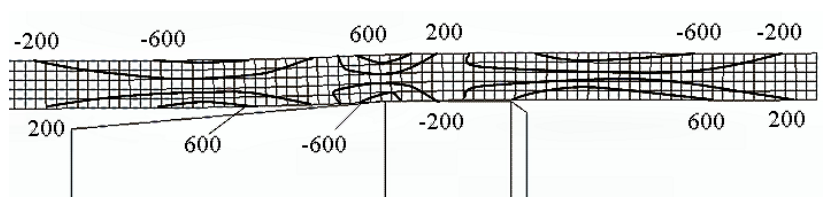

(c) Axial stress (MPa)

Figure 3: Simulated results on single taper plug 


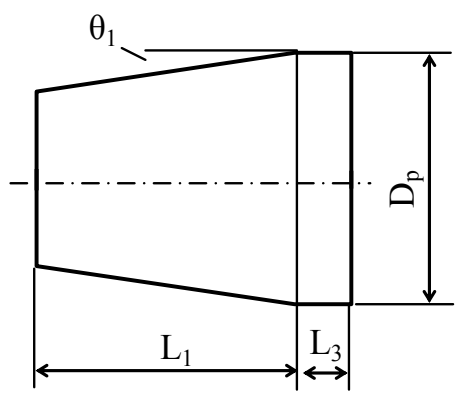

(a) Single taper plug

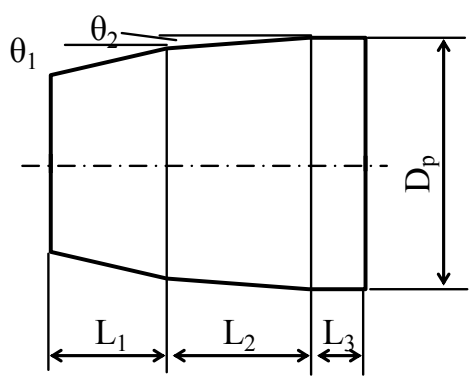

(b) Double taper plug

Figure 4: Comparison of the two plugs

\section{VALIDATION OF NEW PLUG DESIGN}

FEA was carried out using ELFEN on the expansion by a double taper plug. Angle of inlet side taper zone $\theta 1$ is $5^{\circ}$ and that of second taper zone $\theta 2$ is $1^{\circ}$. Other conditions for FEA are the same for the case selected for Fig. 5. The expansion ratio of the inside diameter was $1.5 \%$. The results are illustrated in Figure 5 and 6. It is shown in Fig. 3-(c) and Fig. 5-(b) that the distribution of stress does not change considerably when a double taper plug is adopted. However, it is clearly shown in Fig. 6 that adoption of double taper plug well suppresses the occurrence of overshooting phenomenon. It is considered that in case of using developed plug the inside surface of the end-sized portion is determined by the bearing portion of the plug and the inside diameter of end-sized portion exactly meets the aimed value.

In order to validate the effect of the new plug design, laboratory experiment was carried out by using the parent pipe referred in the FEA. A test piece of $300 \mathrm{~mm}$ in length was cut out of the parent pipe and was subjected to expansion using a double taper plug. The plug was press into the test piece through the other end and three dimensional measurement of the expanded geometry was carried out. The results are indicated in Figure 7. Obviously considerable improvement of the inside geometry is observed on the expanded pipe, and it must be noted that the improvement by the double taper plug is much better than that by a single taper plug.

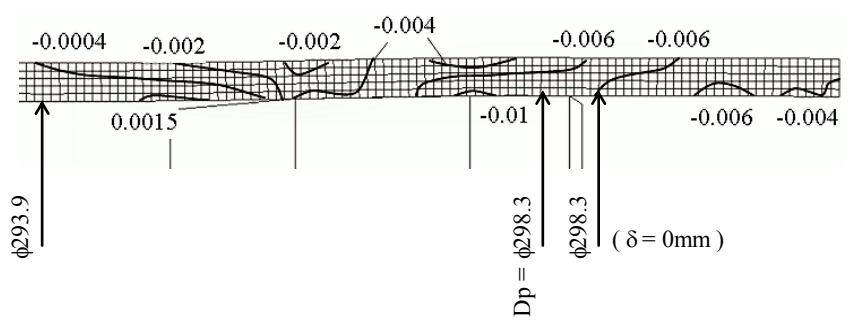

(a) Axial strain

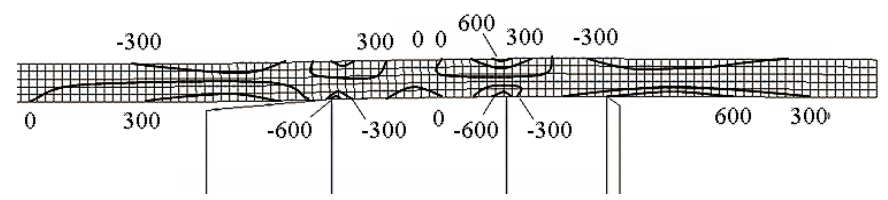

(b) Axial stress (MPa)

Figure 5: Simulation results on double taper plug 


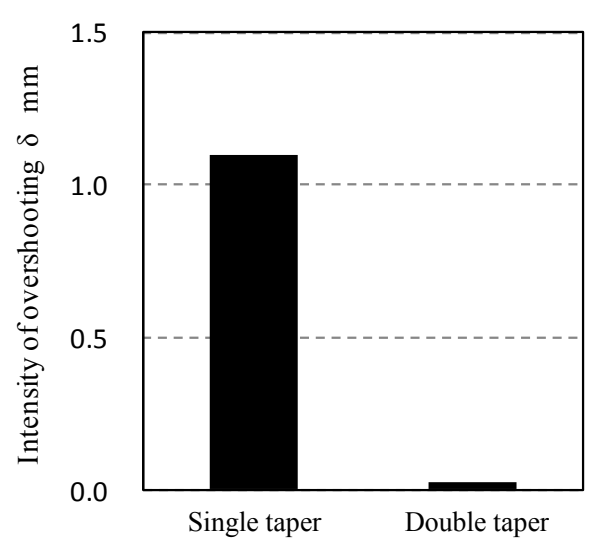

Figure 6: Effect of new plug design by FEA

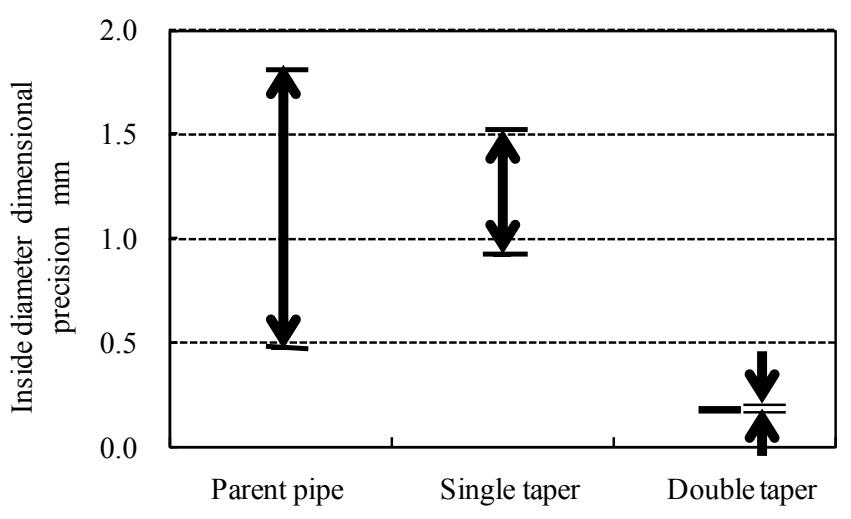

Figure 7: Validation of new plug design in laboratory

\section{NEW PRODUCTION LINE}

The experimental data in the laboratory lead to the decision on the installation of a new end-sizing machine. The maximum length of end-sizing portion is $300 \mathrm{~mm}$. The operational range covers the outside diameter of pipe up to 16 inches. The outline of the machine is shown in Figure 8. Four thick columns ensure high rigidity of the machine and concentricity between the clump portion and the tool realizes a stable end-sizing operation.

On the downstream end of the new end-sizing line, new measuring equipment was installed to measure the geometry of outside and inside surfaces of the end-sized portion. Figure 9 is the view of the measuring equipment. It measures the geometry of end-sized portion in the circumferential direction in a specified pitch in the axial direction.

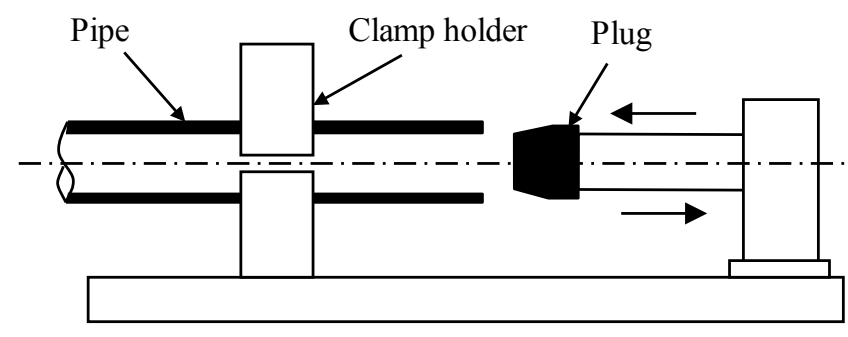

Figure 8: New press machine for end-sizing

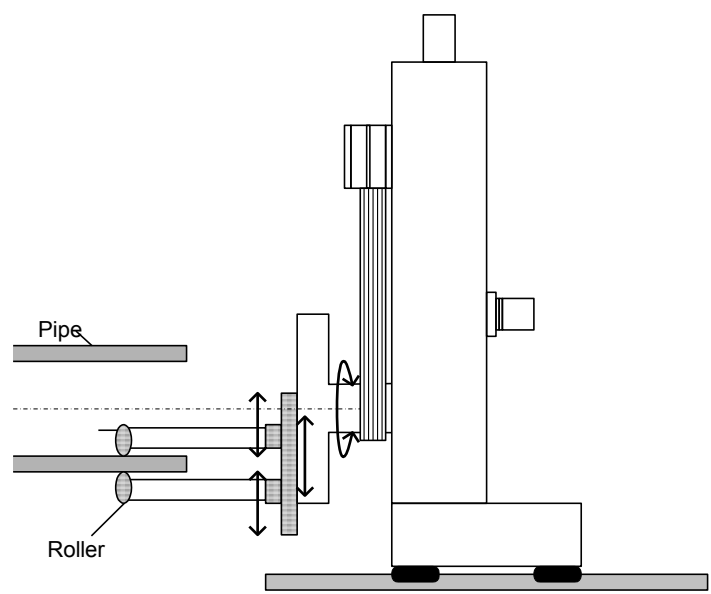

Figure 9: New measuring equipment for end-sized line pipes 


\section{RESULTS}

End-sizing by cold expansion was applied to a number of pipes and the geometries were compared between the pipes before and after end-sizing operation. The result is shown in Figure 10. The size of parent pipe was different from that for the preliminary test in the laboratory and the outside diameter was $355.6 \mathrm{~mm}$ and the wall thickness was $22 \mathrm{~mm}$. The ratio of expansion in inside diameter was $0.8 \%$. Although considerable amount of eccentricity was observed on the parent pipes, it was reduced after end-sizing and the dimension of inside diameter fell within a very narrow range of dimensional precision. The precision is good enough to fall within the range of $\pm 1.6 \mathrm{~mm}$ which is one of the present tolerances specified by the customers.
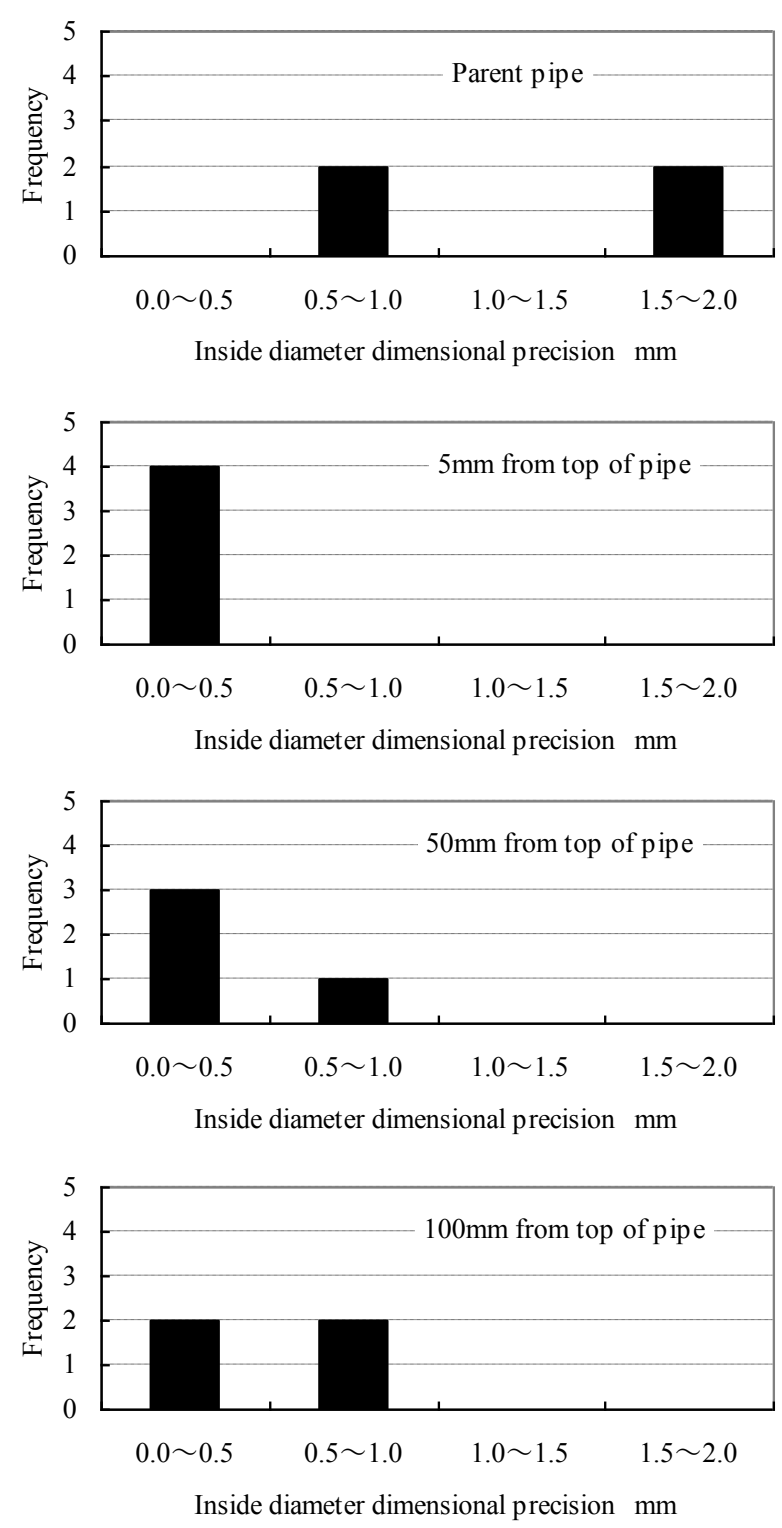

Figure 10: Effect of new end-sizing line 


\section{CONCLUSIONS}

A new end-sizing line specifically for line pipes was built equipped with a new press machine for end-sizing operation and new equipment for measuring the geometry of endsized portion. The key technology for ensuring high precision of end-sized portion is the geometry of the plug used for end-sizing. A double taper plug was proposed for this purpose and FEA was carried out to select an appropriate geometry of the plug. The key design of the plug is that allowing a small amount of additional expansion on the second taper portion. If the design is appropriate the inside surface smoothly fits the bearing portion of the plug and the inside diameter of the end-sized portion exactly meets the aimed value both in the cross section and in the axial direction. The results of laboratory test and field operation showed that high dimensional precision is achievable by adopting a new plug design. The end-sized line pipes manufactured through the new end-sizing line definitely contribute to the efficiency of automated field operation of welding adjacent line pipes.

\section{REFERENCES}

[1] Okui, T., Kuroda, K., and Akiyama, M., 2006, "Die design for reducing tube outside diameter by cold press and mechanism of thinning and bending phenomenon", Ironmaking and Steelmaking, Vol. 33, No. 3, pp. 223-228.

[2] Okui, T., Kuroda, K., and Akiyama, M., 2006, "Suppression of bending phenomenon of steel tube in reducing diameter by cold press", Journal of Engineering Manufacture Proceedings of the Institution of Mechanical Engineers Part B, Vol. 220, pp. 627-636.

[3] Okui, T., Kuroda, K., and Akiyama, M., 2006, "Die, Method of Manufacturing Stepped Metal Pipe or Tube, and Stepped Metal Pipe or Tube" International Publication No. WO2006/025369.

[4] Okui, T., Kuroda, K., and Akiyama, M., 2006, "Mechanism and Suppression of Excessive Decrease in Outside Diameter and Bending Phenomenon in Cold-Reduction of Steel Tube Diameter", Journal of the Japan Society for Technology of Plasticity, Vol. 47, No. 542, pp. 210-215.

[5] Okui, T., Kuroda, K., and Akiyama, M., 2006, "Suppression of Excess Deformation on Top Portion of Steel Tube after Cold-Reducing through Die", Journal of the Japan Society for Technology of Plasticity, Vol. 47, No. 544, pp. 368-372.

[6] Okui, T., Kuroda, K., and Akiyama, M., 2006, "Plug, Method of Expanding Inside Diameter of Metal Pipe or Tube Using Such Plug, Method of Manufacturing Metal Pipe or Tube", International Publication No. WO2006/033376.

[7] Rockfield Software Limited, For the details of ELFEN, please contact Rockfield Software Limited, Technium, King's Road, Prince of Wales Dock, Swansea, SA1 8PH, Wales, U.K.. 